\title{
College Networking Using Php and MySQL for Social Connection Between College Students and Faculties
}

\author{
Mrs.Swathi $\mathbf{S}^{1}$, Fayiz Firosh ${ }^{2}$, Nithin $\mathrm{S}^{3}$, Rohith S, Rohith $\mathrm{S}^{4}$ \\ Department of Computer Science and Engineering, JCT College of Engineering and Technology, \\ Coimbatore, Tamil Nadu, India ${ }^{1-4}$
}

\begin{abstract}
Networking is a word that is used a lot nowadays: networking this, networking that. It's almost used so much that the meaning is lost. The gist seems to be: it is something you should be doing and doing a lot. Networking is actually pretty simple, and yes, we agree that you should be doing it! You're familiar with social networks, right? You gain followers on Instagram and add friends on Snapchat. Networking, in the professional sense, is similar in that you're establishing connections with people typically in your field. These connections could be working professionals, experts, thought leaders, or even professors. The purpose of networking is to form relationships with those who'll help get you to where you want to go, and the earlier you start building up your network, the better. That's why it's important to start networking in college — before you're even ready to enter the workforce.
\end{abstract}

\section{INTRODUCTION}

College networking is designed only for students of the college. This project is similar to many popular social networking platforms where the students will be provided with the opportunity to share information. It will also help them to tackle the problems they are facing in the college by highlighting the issue on this platform. One should have to make an account on this platform to get access to all of its features. Students will also be able to get updates related to the college. The creation of an account of anyone other than the college students is restricted. Students can connect by sending friend requests. After this, they can share the information which consists of educational materials and many more. Students are also able to upload their profile pictures on which they can receive likes and comments from the students to whom they connected with. There are also features of forming groups, sharing videos, etc. Students are also able to send messages to each other which is the major feature of any social networking platform.

\section{RELATED WORK}

\section{Structure of the project}

Many things are to be considered in the making of this project. Some of the things which are to be looked at are DFD diagrams, database, system design, etc. The system design is the skeleton of the actual project which includes components like student profile and admin control. The student profile includes the details of the profile, information on uploading files, etc. Students from any part of the world can connect with the help of this platform. They just have to log on to their account after the account getting approved by the admin.

\section{Privileges}

The privileges provided on this platform varies from the students to the admin. The students can update their profiles by adding various educational details. They can upload files and can share it with their friends on this platform or to a certain group. The privileges of the admin are the highest. Admins are not only provided with the feature which is available to the students but also with the privilege to modify the database of this project. Admins have the right to ban any member if in case that member violates the policies of this platform.

\section{Community}

The students can contact the community of this platform in case of any problem. These problems include all the bugs related to this platform or in case of any difficulty found by the students. They are also able to report other accounts in case of any inappropriate action performed by such accounts. This platform will help the students to connect with their friends and can share meaningful information. 
International Journal of Innovative Research in

Electrical, Electronics, Instrumentation and Control Engineering

Vol. 9, Issue 5, May 2021

DOI 10.17148/IJIREEICE.2021.9506

\section{METHODOLOGY}

When the requirements document for the software to be developed is available, the design activity begins. The main aim of design process is to produce a model or representation of the system, which can be used later to bind the system. The produced model is called design of the system. A system design is a top down approach to minimize complexity and make a problem manageable by subdivided it into smaller segments. The most changing phase of the system development of life cycle is system design. It refers to the technical specification that will be applied in implementing the candidate system. The design phase is a translation from user oriented document to document oriented to programmers. The potential objects are thoroughly analysed. Class hierarchies are to check whether the system is behaving the way it has to. There after the classes are individually tested and subsequently they are integrated from the overall system. This level focuses on deciding which modules are needed for system the specifications for those modules and how these modules are that interconnected.

\section{Logical Design:}

A logical data flow diagram shows the flow of data through a transaction processing system without regard to the time period when the data flows or the processing procedures occur.

\section{Physical Design:}

The physical design maps out the details of physical systems, plans the system implementations, device a test and implementation plan and specifies any new hardware and software.

\section{Objective of the system:}

The main purpose of creating Campus Networking Site is for meeting worldwide college students and sharing knowledge, education related information's, etc. It contains standard social network content, like profiles, pictures, email and groups, and video sharing, articles, etc. Student can create a profile, browse locations worldwide, share and collect knowledge, education related tutorials, etc.

\section{Applicable document:}

Profile detail: It holds student profile information.

Education detail: It has education articles, tutorials, videos, photos and any other information.

Upload detail: It holds uploaded images, videos, tutorials and any other information's.

\section{Functional decompositions:}

- Student profile.

- $\quad$ Education profile.

- $\quad$ Education articles.

- Images, videos, etc.

- Quiz, question-answers etc.

\section{Functional components and design assumptions.}

The Campus network can help you maintain existing relationships with people and share pictures and messages, and establish new ones by reaching out to people you've never met before, an also using this site user can share Knowledge's, education related books, question/answer, and any other information. 
International Journal of Innovative Research in

Electrical, Electronics, Instrumentation and Control Engineering

Vol. 9, Issue 5, May 2021

DOI 10.17148/IJIREEICE.2021.9506

\section{Some of the symbols used in data flow diagram}

\begin{tabular}{|l|l|}
\hline & $\begin{array}{l}\text { The process shows a transformation or manipulation of } \\
\text { dataflow with in a system. A process transforms in } \\
\text { coming data flow into outgoing data flow. }\end{array}$ \\
\hline & $\begin{array}{l}\text { A database is a holding place for information within the } \\
\text { system it is represented by an open ended narrow } \\
\text { rectangle. }\end{array}$ \\
\hline & $\begin{array}{l}\text { External entities are outside the system but they either } \\
\text { supply input data into the system or use the system output. } \\
\text { External entities are represented by rectangle. }\end{array}$ \\
\hline & $\begin{array}{l}\text { a dataflow shows flow of information form source to } \\
\text { destination a data flow represented }\end{array}$ \\
\hline
\end{tabular}

\section{Description of the program}

The customer switch diagram for online campus networking is shown in the figure below. The input and output of this section is shown in the diagram, however no of details about the function of the online campus networking system is given here. Using this as a starting point, a logical DFD of the system is developed.

\subsection{Context flow diagram:}

The environment in which the software used is depicted in this picture. The CFD shows the external entity action on the software is shown here in CFD as a single process.

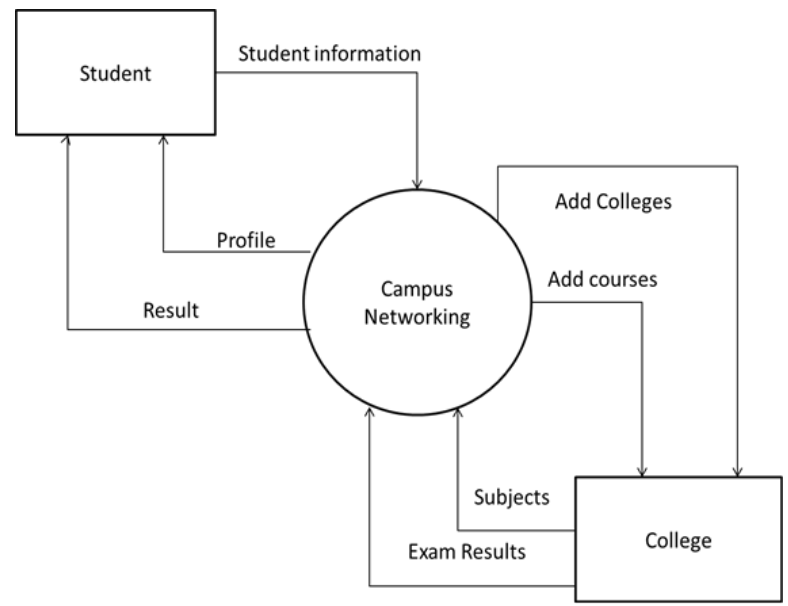

\subsection{Top level DFD:}

Top level DFD shows the functional component in the software package. each component shown in the top level DFD is described in the subsections. 
International Journal of Innovative Research in Electrical, Electronics, Instrumentation and Control Engineering

Vol. 9, Issue 5, May 2021

DOI 10.17148/IJIREEICE.2021.9506

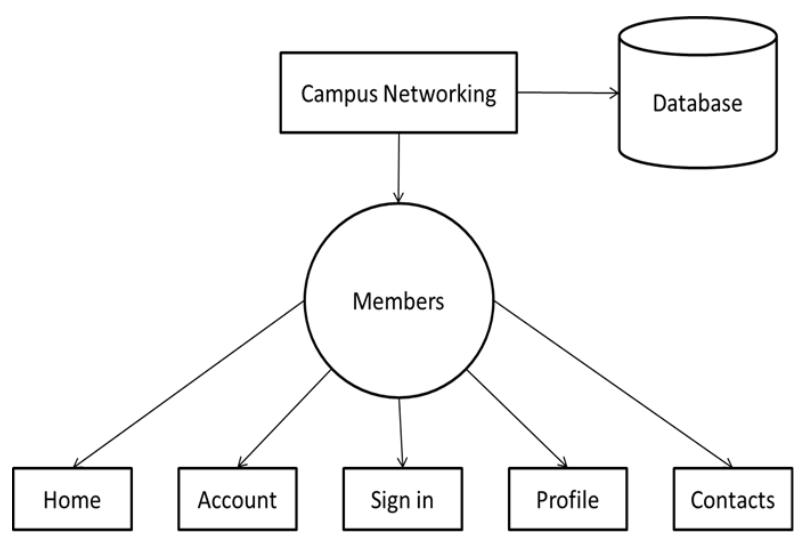

\subsection{Description of the components}

\subsubsection{Functional component 1: Student Profile}

Input- Student adds profile information and education details

Process- System checks previous student account and education details.

Output- Student can view education detail and profile details.

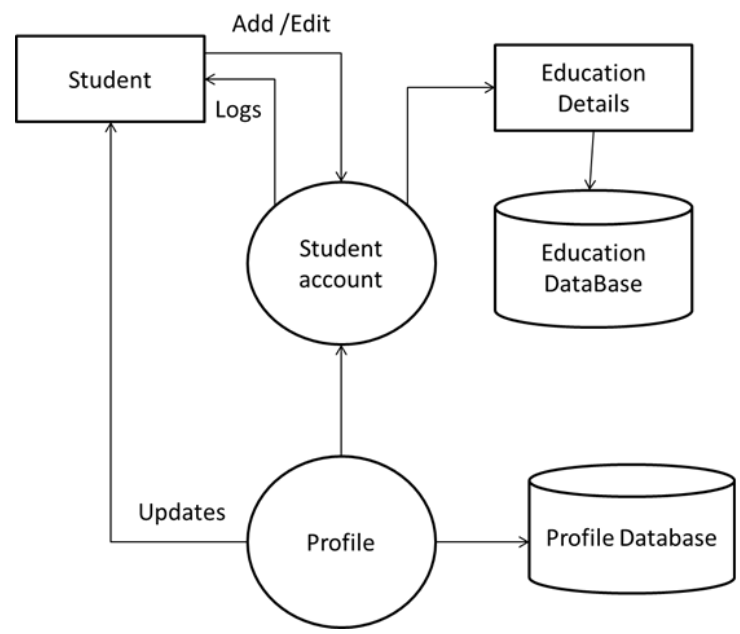

\subsubsection{Functional component 2: Tutorials}

Input- Student uploads education articles, tutorials, images, videos etc.

Process- System uploads education articles, tutorials, images, videos to database.

Output- Student can view uploaded education articles, tutorials, images, videos etc. 
International Journal of Innovative Research in Electrical, Electronics, Instrumentation and Control Engineering

Vol. 9, Issue 5, May 2021

DOI 10.17148/IJIREEICE.2021.9506

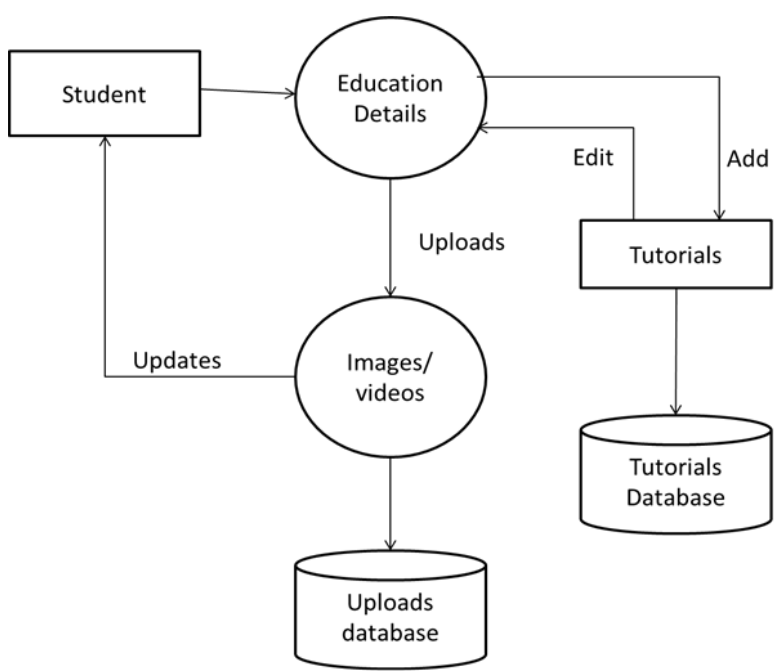

\subsubsection{Functional component 3: Admin}

Input- Admin can upload and share video tutorials, question papers, books etc.

Process- System uploads education tutorials, question papers, books to database.

Output- Student can view uploaded tutorials, question papers, books etc.

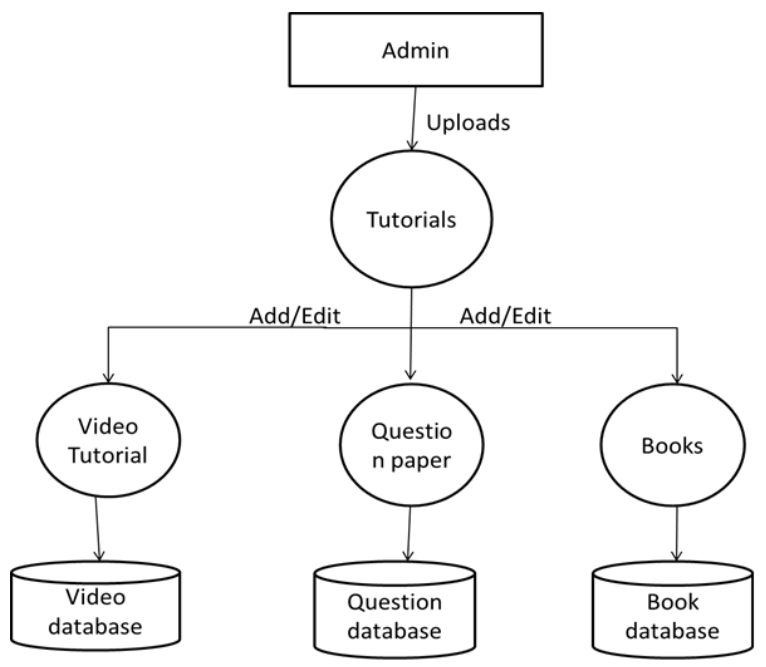

\section{CONCLUSION}

Now that you know the importance of networking in college, you can begin developing your path for your future postgraduation. You want to do whatever it takes to get that job you dream of and use the degree you earned. Networking is one of the most important parts of reaching this goal. It can help you build a bridge from academic success to career success. Several groups can be formed on certain topics to get updates related any information. These groups play a major role in highlighting the issues caused by an individual or a group of colleges. This makes this social networking platform an amazing one for the students as they can get connected and can share important information. With this college networking website application, you can connect with friends, find old friends, share pictures and messages, and reach out to new people registered into the application you've never met before. There may be rooms for enhancements and improvements in this project, so students are recommended to work on that to make this application a better one.

\section{FUTURE SCOPE}

It may seem like all college students are using technology at all times, and generally speaking, there is truth to that statement. Most college students come to campus with multiple technology devices, using their devices for reasons both academic and personal. Academically this project is going to help the students at present and for the future college 
International Journal of Innovative Research in

Electrical, Electronics, Instrumentation and Control Engineering

Vol. 9, Issue 5, May 2021

DOI 10.17148/IJIREEICE.2021.9506

students which will benefit them with the up to date information, career oriented and even personal behavioural development by meeting new students and faculties all over the world.

\section{REFERENCES}

[1] J. F. Kurose and W. R. Ross, Computer Networking: A Top-Down Approach Featuring the Internet.

[2] L.L. Peterson and B. S. Davie, Computer Networks: A System Approach.

[3] Andrew S.Tanenbaum, Computer Networks

[4] Systems Analysis and Design Second Edition, 1998; By Elias M. Awad

[5] Software Engineering Fifth Edition, 2001; By Roger S. Pressman, Ph.D.

[6] SQL for SQL Server, First Indian Edition 2003; By Bryan Syverson

[7] Visual Basic 6 Database How - To, First Indian Edition 1999; By Eric Winemiller, Jason Roff, Bill Heyman, Ryan Groom

[8] SQL, PL/SQL, Second Revised Edition; By Ivan Bayross

[9] Visual Basic 6 Super Bible, First Indian Edition 1999; By David Jung, Pierre Boutquin, John D. Conley III, Loren Mauer, Jack Purdum

[10] An Introduction to Database Management System, Bipin C. Desai. 